\title{
Two-Step Leaching of Valuable Metals from Discarded Printed Circuit Boards, and Process Optimization Using Response Surface Methodology
}

Arda Işıldar ${ }^{1,2^{\star}}$, Eldon R Rene ${ }^{1}$, Eric $\mathbf{D}$ van Hullebusch ${ }^{1,2}$ and Piet $\mathbf{N}$ L Lens ${ }^{1,3}$

${ }^{1}$ Department of Environmental Engineering and Water Technology, UNESCO-IHE Institute for Water Education, Post Box 3015,2601 DA Delft, The Netherlands

${ }^{2}$ Laboratory Geomaterials and Environment (LGE), University Paris-Est, EA 4508, UPEM, 77454 Marne Valley, France

${ }^{3}$ Department of Chemistry and Bioengineering, Tampere University of Technology, PO Box 10 541, Tampere, Finland

*Corresponding author: Işıldar A, Department of Environmental Engineering and Water Technology, UNESCO-IHE Institute for Water Education, PO Box 3015, 2601 DA Delft, The Netherlands, Tel: +31(0)152151715; E-mail: ardaisildar@gmail.com

Received date: May 12, 2017; Accepted date: May 20, 2017; Published date: May 26, 2017

Copyright: (c) 2017 Işıldar A, et al. This is an open-access article distributed under the terms of the Creative Commons Attribution License, which permits unrestricted use, distribution, and reproduction in any medium, provided the original author and source are credited.

\begin{abstract}
Waste electrical and electronic equipment (WEEE) is an important secondary source of valuable metals. Particularly discarded printed circuit boards (PCB) contain high concentrations of valuable metals, varying greatly among the type of board, the manufacture year, source device, and utilized PCB production technology. Chemical hydrometallurgical processing is an efficient method to selectively extract and subsequently recover metals from discarded polymetallic PCB. In this work, we propose a two-step process to extract copper $(\mathrm{Cu})$ and gold $(\mathrm{Au})$ from a discarded high-grade telecom server PCB. The boards contained 262.4 and $0.320 \mathrm{mg} / \mathrm{g} \mathrm{Cu}$ and Au, respectively, which constituted the $98.1 \%$ of the total value of metals. The metal extraction process was optimized using Response Surface Methodology (RSM) by central composite design (CCD). The optimized process parameters showed that $3.92 \mathrm{M}$ sulphuric acid, $3.93 \mathrm{M}$ Hydrogen peroxide, $6.98 \%(\mathrm{w} / \mathrm{v})$ pulp density and 3.7 hours contact time, and $0.038 \mathrm{M}$ Copper sulphate, $0.3 \mathrm{M}\left(\mathrm{S}_{2} \mathrm{O}_{3}^{2-}\right) 0.38 \mathrm{M}$ Ammonium Hydroxide, $10.76 \%$ pulp density (w/v) 6.73 hours were optimal for the maximal extraction of $\mathrm{Cu}$ and $\mathrm{Au}$, respectively. At optimal conditions, $99.2 \%$ and $92.2 \%$ of $\mathrm{Cu}$ and $\mathrm{Au}$, respectively, were extracted from the discarded PCB.
\end{abstract}

Keywords: Response surface methodology; Gold; Copper; Printed circuit boards; Telecom board; High-grade

\section{Highlights}

- $\mathrm{Cu}$ was leached with sulfuric acid $\left(\mathrm{H}_{2} \mathrm{SO}_{4}\right)$ and hydrogen peroxide (sulphuric acid).

- Au was leached with thiosulfate catalyzed by cupric ions $\left(\mathrm{Cu}^{2+}\right)$.

- Statistical optimization was applied using Response Surface Methodology (RSM).

- Under optimized conditions, $92.2 \%$ and $99.2 \%$ of $\mathrm{Cu}$ and $\mathrm{Au}$, respectively, were removed.

- Confirmatory tests validated the model reliability with a high confidence level.

\section{Introduction}

Discarded printed circuit boards (PCB) are an important secondary source of valuable metals. All electrical and electronical equipment (EEE) contain PCB [1] of various size, type and composition [2]. These materials are a complex mixture of metals, polymers and ceramics [3]. Low lifespan of electronic devices [4], perpetual innovation in electronics [5] and affordability of the devices [6] resulted in an unprecedented increase of waste electrical and electronic equipment (WEEE). In 2014, global WEEE generation was 41.8 million tons (Mt), of which 9.5, 7.0 and $6.0 \mathrm{Mt}$ belonged to the EU-28, USA and China, respectively [7], and is expected to increase to $50 \mathrm{Mt}$ in 2018 [8]. The hazards associated with improper WEEE management brings along two fold problems:
1. degradation of the environment [9] and

2. loss of valuable natural resources [10].

Despite its potential toxicity, WEEE contains valuable materials that could be recovered to conserve primary resources and prevent greenhouse gas emissions [11] coupled with potential economic benefits through the recovery of valuable metals.

WEEE is a complex mixture of materials in various concentrations. Modern devices encompass up to 60 elements, with an exponential increase of complexity in the recent years [12]. These elements go into the manufacture of microprocessors, circuit boards, displays, and permanent magnets in complex alloys [13]. The composition of preprocessed PCB from a WEEE treatment plant is $38.1 \%$ ferrous metals, $16.5 \%$ non-ferrous metals, $26.5 \%$ plastic and $18.9 \%$ others [14]. Precious metals are the main economic driver of WEEE recycling [15], viz. gold $(\mathrm{Au})$ has the highest recovery priority; followed by copper $(\mathrm{Cu})$, palladium $(\mathrm{Pd})$, aluminium $(\mathrm{Al})$, tin $(\mathrm{Sn})$, lead $(\mathrm{Pb})$, platinum $(\mathrm{Pt})$, nickel $(\mathrm{Ni})$, zinc $(\mathrm{Zn})$ and silver $(\mathrm{Ag})$ [16] owing to the individual value and criticality of these metals, On the other hand, the intrinsic value of non-precious metals are increasing [17] due to relatively decreasing concentration of precious metals, and elevated concentration of the technology metals, such as the rare earth elements (REE) $[18,19]$.

Several hydrometallurgical strategies were experimented to extract valuable metals from discarded PCB. Hydrometallurgical metal recovery routes involve an oxidative leaching for the extraction of metals and a subsequent recovery and refining steps [20]. Metal extraction via oxidative acidic or alkaline leaching medium is an essential process for metal recovery from PCB. Leaching of metals 
Page 2 of 9

from discarded PCB in various media including, hydrochloric acid $(\mathrm{HCl})$ [21,22], sulfuric acid [23,24], nitric acid [25,26], often in addition of an oxidant such as hydrogen peroxide [27], ferric iron [28], chloride [29] and oxygen [30] have been reported. Moreover, several novel leachants including thiosulfate $\left(\mathrm{S}_{2} \mathrm{O}_{3}^{2-}\right)$ [31,32], thiourea (formula) [33,34] and iodine [35,36] were investigated for their effectiveness to recover valuable metals from waste PCB.

Sulphuric Acid leaching, often in combination with an oxidant is the most common method to extract base metals from their primary and secondary sources [37], including discarded PCB. Sulphuric acid is a strong oxidant (1.8 V relative to SHE) which is commonly used in combination with acids to enhance metal extraction yields and kinetics. The oxidation reaction is exothermic and control of the temperature may be needed [38]. Concentrations of the lixiviant and the oxidant (sulphuric acid) are the most influential factors affecting metal extraction from WEEE. Earlier studies investigated Sulphuric Acid leaching of $\mathrm{Cu}$ from discarded $\mathrm{PCB}$ at non-optimized high reagent concentrations and with addition of an electro-generated oxidation agent, which typically led to high metal extraction efficiencies.

Precious metal leaching with $\left(\mathrm{S}_{2} \mathrm{O}_{3}^{2-}\right)$ is a non-toxic alternative to cyanidation for primary ores and secondary raw materials. Au leaching rates can be faster than conventional cyanidation, a lower interference from other cations is prevalent, a high yield can be obtained, and a fullscale operation can be more cost-effective than cyanidation [39]. $\left(\mathrm{S}_{2} \mathrm{O}_{3}^{2-}\right)$ in presence of $\mathrm{NH}_{4}^{+}$and cupric ions leaches and complexes precious metals such as gold $(\mathrm{Au})$ and silver (Ag). It allows the solubilisation of $\mathrm{Au}$ as a stable anionic complex at alkaline or nearneutral solutions [39]. Cupric acts as a catalyst in the dissolution reaction, and $\mathrm{NH}_{4}^{+}$as a stabilizing agent of the system and thereby accelerate the anodic dissolution.

The leaching of metals from the waste material is a complex and multivariable process which depends on several physical and chemical parameters and their reciprocal interaction. Factorial design of experiments (DoE) is a powerful tool to analyse the process parameters. Central composite design (CCD) with response surface methodology (RSM) is a robust statistical tool whereby multiple parameters and their interaction influence are involved in the selected response. RSM is increasingly used in hydrometallurgical processing of ores in order to maximize the yield under optimal process parameters. CCD with RSM simultaneously compute several involved factors at various levels and analyse the model for the relation between the various factors and their response [40].

In this study, we propose a multi-step leaching procedure for $\mathrm{Cu}$ and Au recovery from discarded PCB. In the first stage, Sulphuric acid leaching of $\mathrm{Cu}$ in the presence of sulphuric acid is carried out. In the second step, Au leaching using $\left(\mathrm{S}_{2} \mathrm{O}_{3}^{2-}\right)$ as the lixiviant with Copper as catalyzer in ammoniacal medium is carried out. In Cu leaching step, four operational parameters, namely sulfuric acid sulphuric acid concentration, hydrogen peroxide sulphuric acid concentration, contact time (h) and pulp density (PD) (\%, w/v) are optimized to maximize $\mathrm{Cu}$ yield. Similarly, in the proceeding Au leaching step, five operational parameters, namely $\left(\mathrm{S}_{2} \mathrm{O}_{3}^{2-}\right)$ concentration, copper sulfate concentration, ammonium hydroxide concentration, contact time (h) and PD (\%,w/v) were optimized to maximize Au yield.
Finally, the model predictions were compared to experimental data in confirmatory tests.

\section{Materials and Methods}

\section{Source, preparation and characterization of the Printed Circuit Boards (PCB)}

Discarded printed circuit boards (PCB) from telecom server devices and desktop computers were collected from SIMS Recycling in Eindhoven, and the IT department of UNESCO-IHE, the Netherlands. The samples preparation and microwave-assisted acid digestion were carried in a laboratory microwave unit (CEM, MARS, USA) in mixture of nitro-hydrochloric acid and $\mathrm{HCl}, 1: 3$ by volume) as described in our earlier work. After the milling of each sample, the ground materials were sieved to particle sizes of $<500 \mu \mathrm{m}$ to be used in leaching experiments. The digestates and the leachates were serially diluted for metal analysis. The metals prices were taken from the London Metal Exchange in a 1 year period between 1 August 2015 and 1 August 2016, for the total value analysis.

\section{Design of Experiments (DoE) and optimization}

Design of experiments (DoE) is a statistical tool to the analyze and optimize the independent process variables for maximum efficiency by evaluating the interactive effects of operational parameters and minimizing the number of experiments [41]. Central composite design (CCD) was used to study effects of variation of parameters together with response surface methodology (RSM). For the maximal metal yield from the discarded boards, RSM provided statistically supported DoE and mathematical methods for model design, analysis of interaction of the process parameters for the two-step leaching of metals, and the computation of optimal conditions for the parameters.

The total number of experiments was calculated using a factorial design (2k) as given in Equation 1

$$
\mathrm{N}=2 \mathrm{k}+2 \mathrm{k}+\mathrm{n}(1)
$$

where $(\mathrm{N})$ is the total number of experiments, $\mathrm{k}$ is the number of process variables, and $\mathrm{n}$ is the number of replicates, i.e., the center points.

Two CCDs were designed, each with two level factorial points, axial points and central points for the optimization of the two-step $\mathrm{Cu}$ and $\mathrm{Au}$ leaching process (Table 1). The responses for $\mathrm{Cu}$ yield $(\mathrm{mg} \mathrm{Cu} / \mathrm{g}$ $\mathrm{PCB}$ ) and $\mathrm{Au}$ yield (mg Au/100 mg PCB) were computed. Levels of coded and assigned variables, and each factor was studied at 5 different levels $(-\alpha,-1,0,1,+\alpha)$ in the design. MINITAB 17 (Minitab Inc, USA) was used to analyze the interaction of independent process variables for the RSM study. In the first $\mathrm{Cu}$ leaching step, 31 experimental runs including 24 full factorial experiments (Runs 1-24), 7 center points (Runs 25-31) with 4 factors and 5 levels were designed. In the second $\mathrm{Au}$ leaching step, 53 experimental runs including 32 full factorial experiment (Runs 1-32) and 17 center points in axis (Runs 43-52) with 5 factors and 5 levels were designed.

For $\mathrm{Cu}$ leaching, sulphuric acid (M), PD (\%,w/v), and contact time (h), whereas for Au leaching, Copper sulphate $(\mathrm{M}),\left(\mathrm{S}_{2} \mathrm{O}_{3}^{2-}\right)(\mathrm{M})$, Ammonium Hydroxide (M), PD (\%, w/v), and contact time (h) were selected as the variable operational process parameters. The selected value ranges for sulphuric acid concentrations were 2.0-6.0 M, the PD was $4.0-10.0 \%(\mathrm{w} / \mathrm{v})$, contact time was $2.0-6.0$ hours, based on 
Page 3 of 9

screening tests and the earlier studies. Similarly, for Au leaching the selected range for both $\left(\mathrm{S}_{2} \mathrm{O}_{3}^{2-}\right)$ and Ammonium hydroxide concentrations was 0.2-0.4 M, for Copper sulphate concentration was 0.025-0.05 M, for the pulp density was $1.0-10.0 \%(\mathrm{w} / \mathrm{v})$ and for contact time was 4.0-8.0 hours. The parameters and their ranges were selected in line with the and the concentration of the metals of interest in the discarded PCB, the results of the screening tests and the published literature which was conducted with similar discarded materials.

\begin{tabular}{|l|l|l|l|l|l|l|l|}
\hline \multirow{2}{*}{ Parameter } & \multirow{2}{*}{ Unit } & \multirow{6}{*}{ Code } & \multicolumn{6}{|l|}{ Range and levels } \\
\cline { 4 - 9 } & & & $-\alpha$ & -1 & 0 & 1 & $+\alpha$ \\
\hline \multicolumn{7}{|l|}{ Copper leaching yield } \\
\hline $\mathrm{H}_{2} \mathrm{SO}_{4}$ & (M) & A & 0 & 2 & 4 & 6 & 8 \\
\hline $\begin{array}{l}\text { Sulphuric } \\
\text { acid }\end{array}$ & (M) & B & 0 & 2 & 4 & 6 & 8 \\
\hline PD & $(\%, w / v)$ & C & 1 & 4 & 7 & 10 & 13 \\
\hline Time & (h) & D & 0 & 2 & 4 & 6 & 8 \\
\hline
\end{tabular}

Gold leaching yield

\begin{tabular}{|l|l|l|l|l|l|l|l|}
\hline $\mathrm{CuSO}_{4}$ & $(\mathrm{M})$ & $\mathrm{A}$ & 0 & 0.025 & 0.0375 & 0.05 & 0.75 \\
\hline $\mathrm{NH}_{4} \mathrm{OH}$ & $(\mathrm{M})$ & C & 0 & 0.2 & 0.3 & 0.4 & 0.6 \\
\hline $\mathrm{PD}$ & $(\%$, w/v $)$ & D & 2 & 4 & 6 & 8 & 12 \\
\hline Time & $(\mathrm{h})$ & E & 0 & 2.5 & 3.75 & 5 & 7.5 \\
\hline
\end{tabular}

Table 1: CCD of parameters from low to high levels for copper $(\mathrm{Cu})$ and gold $(\mathrm{Au})$ leaching.

\section{Confirmatory leaching experiments}

Additional sets of confirmation tests were carried out in order to endorse the validity and reliability of RSM model predictions. The operational parameters of confirmation experiments were selected as per the CCD design and the results of the RSM study (optimal and -1 values), plus control tests. Discarded PCB were put in contact with the leachant and oxidant in $100 \mathrm{~mL}$ Erlenmeyer flasks that were closed with a septum screw cap. The flasks were agitated at $150 \mathrm{rpm}$ and at constant ambient temperature $\left(23 \pm 2^{\circ} \mathrm{C}\right)$. Periodic metal analyses $(5$ $\mathrm{mL}$ ) were carried out by using sampling syringes. The alteration in liquid-to-solid ratio due to sampling was considered in calculations, and the metal concentrations were reported with a correction factor. The analytes were centrifuged at $1000 \mathrm{rpm}$ for $10 \mathrm{~min}$, filtered (Whatmann $0.45 \mu \mathrm{m} \mathrm{G/C}$ ), and serially diluted for metal measurements.

At the end of the first leaching step, the residues were collected and characterized for their total metal content per the procedure described in 2.1. In the following Au leaching experiments, residues from the preceding leaching step were washed two times with ultrapure water and put in contact with the leachant, oxidant and catalyser solutions in $100 \mathrm{~mL}$ Erlenmeyer flasks. The flasks that were closed with a septum screw cap and agitated at $150 \mathrm{rpm}$ at constant ambient temperature (23 $\pm 2^{\circ} \mathrm{C}$ ). Each test was carried out in duplicate.

\section{Analytical methods}

The metal analyses were performed by inductively coupled plasma mass spectrometer (ICP-MS) (X series 2, Thermo Scientific, USA) and inductively coupled plasma optical emission spectrometer (ICP-OES) (Perkin Elmer, Optima 8300, USA) [41]. Analytical grade chemicals and ultrapure (MiliQ) water were used. Alternatively, periodic metal measurements were carried out by atomic absorption spectrophotometer (AAS-F) (Varian 200, USA). The wavelengths (nm) for $\mathrm{Cu}$ and $\mathrm{Au}$ were 324.752 and 267.595, respectively. The analyzing blanks and calibration standards were performed periodically to establish the reproducibility of the data and assure the analytical quality standards (QA/QC). The statistical analysis of the results was carried out by MINITAB 17 and Microsoft Excel 2016.

\section{Results}

\section{Metal concentrations and intrinsic value of the discarded PCB}

The copper $(\mathrm{Cu})$ and gold $(\mathrm{Au})$ concentrations of the discarded telecom and desktop PCB are shown in Table 2. The telecom PCB had a higher concentration of both metals over regular computer PCB. The intrinsic value of $\mathrm{Au}$ was higher in telecom boards, owing to its high concentration in telecom PCB (15.2 factor). The intrinsic value of $\mathrm{Cu}$ and $\mathrm{Au}$ was 51.6 and 41.3 respectively for desktop PCB, on the other hand, the intrinsic value of $\mathrm{Au}$ and $\mathrm{Cu}$ in Telecom PCB was 85.8 and 11.3, respectively. Considering the value of all the metals (concentrations not shown) found in the discarded PCBs, $\mathrm{Cu}$ and $\mathrm{Au}$ constituted the vast majority of the total value. These two metals made up $91.9 \%$ and $97.1 \%$ of the total value for discarded desktop and telecom PCB, respectively.

\begin{tabular}{|l|l|l|}
\hline Metals & Cu (mg/g PCB) & Au $(\mu \mathrm{g} / g$ PCB) \\
\hline Telecom board & $262.4 \pm 16.6$ & $320.7 \pm 17.1$ \\
\hline Intrinsic value (\%) & 11.3 & 85.8 \\
\hline Desktop computer & $176.7 \pm 23.6$ & $21 \pm 3.2$ \\
\hline Intrinsic value (\%) & 51.6 & 41.3 \\
\hline
\end{tabular}

Table 2: Metal concentrations (mg/g PCB) of the discarded printed circuit boards.

\section{Optimization of the metal extraction process using Response Surface Methodology (RSM)}

Optimization and desirability function: The desirability functions for $\mathrm{Cu}$ and $\mathrm{Au}$ leaching are given in Figure 1. Response surface methodology (RSM) using central composite design (CCD) for $\mathrm{Cu}$ and $\mathrm{Au}$ leaching determined the optimized process parameters for the maximal yield of the two metals. The optimal value for the maximized response of multiple influencing factors i.e., leachant, oxidant and catalyzer concentrations, pulp density (PD), and contact time were considered to directly influence the yield of metals extracted from discarded PCB.

A desirability function was incorporated to achieve the maximum metal extraction yield for each leaching step. For the ranges selected, viz., 2.0-6.0 M Sulphuric acid, 2.0-6.0 M sulphuric acid, 1.0-10.0\% $(\mathrm{w} / \mathrm{v})$ pulp density and $0.0-6.0 \mathrm{~h}$ contact time, the desirability function 
Citation: Isildar A, Rene ER, Hullebusch EDV, Lens PNL (2017) Two-Step Leaching of Valuable Metals from Discarded Printed Circuit Boards, and Process Optimization Using Response Surface Methodology. Adv Recycling Waste Manag 2: 132. doi:10.4172/2475-7675.1000132

Page 4 of 9

for the maximum for $\mathrm{Cu}$ yield is given in Figure 2a. Similarly, for $\mathrm{Au}$ leaching 0.025-0.05 M Copper sulphate, 0.2-0.4 $\mathrm{M}\left(\mathrm{S}_{2} \mathrm{O}_{3}^{2-}\right), 0.2-0.4 \mathrm{M}$ Ammonium Hydroxide, $4.0-8.0 \%$ pulp density (\%, w/v), and 2.5-5.0 h contact time, the desirability function is given in Figure $1 \mathrm{~b}$. These values were used to perform confirmatory tests under the optimized conditions to ascertain the reliability of the model.

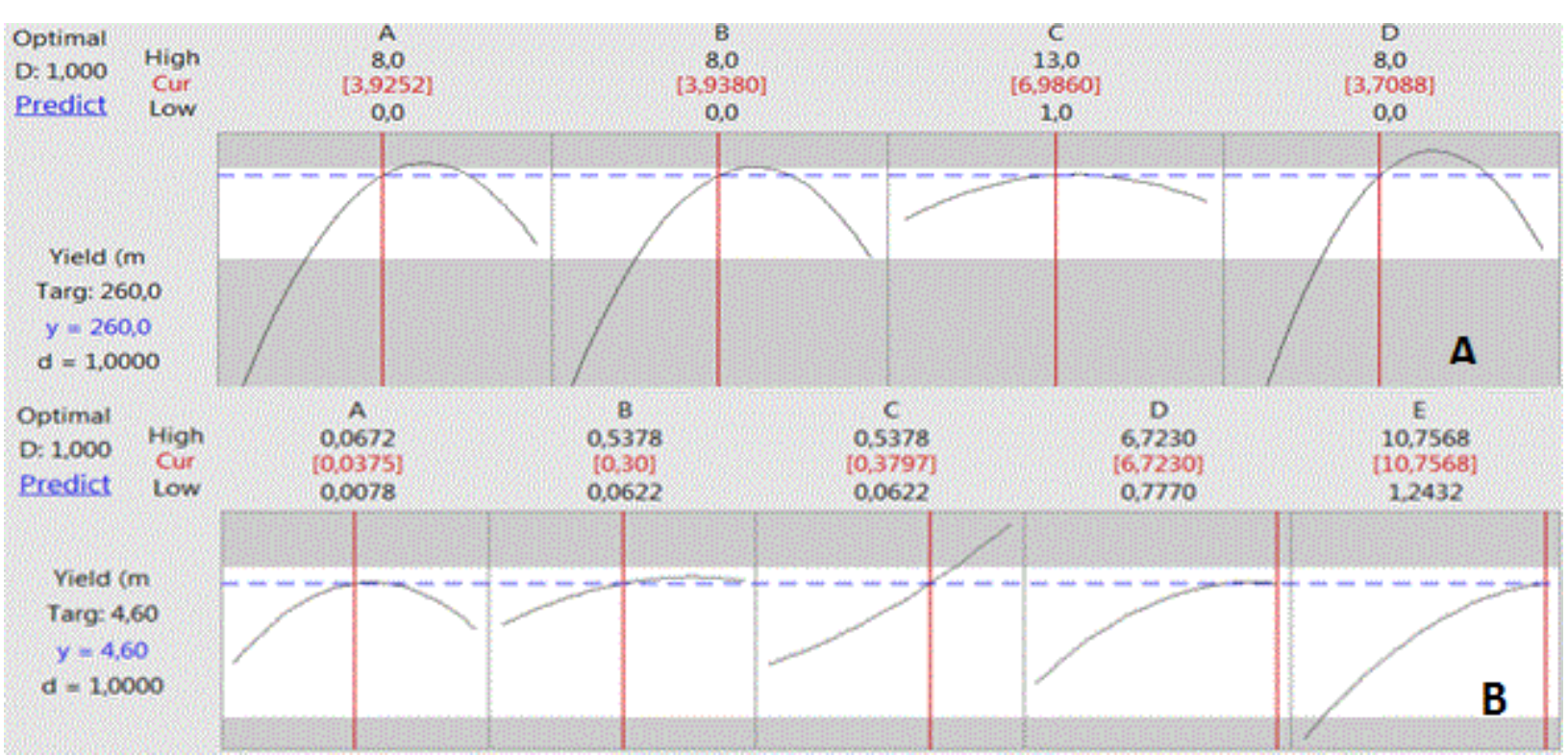

Figure 1: Desirability functions for (a) Cu for (A) $\mathrm{H}_{2} \mathrm{SO}_{4}(\mathrm{M})$, (B) sulphuric acid (M), (C) pulp density (\%, w/v), and (D) contact time (h) and (b) gold leaching and for (A) $\mathrm{CuSO}_{4}(\mathrm{M}),(\mathrm{B}) \mathrm{NH}_{4} \mathrm{OH}(\mathrm{M}),(\mathrm{C})$ pulp density (\%, w/v), and (D) contact time.

\section{Regression equation of $\mathrm{Cu}$ yield is shown below in Equation 2:}

$\mathrm{Y}=-243+61.8 \mathrm{~A}+58.3 \mathrm{~B}+5.6 \mathrm{C}$

$+77.2 \mathrm{D}-6.81 \mathrm{~A}_{2}-6.68 \mathrm{~B}_{2}-0.692 \mathrm{C}_{2}-8.46 \mathrm{D}_{2}+0.27 \mathrm{AB}+0.57 \mathrm{AC}+0.61 \mathrm{AD}$

$+0.30 \mathrm{BC}+1.08 \mathrm{BD}+0.45 \mathrm{CD} \quad$ (2)

where $\mathrm{Y}$ represents the $\mathrm{Cu}$ yield in $(\mathrm{mg} / \mathrm{g} \mathrm{PCB}),(\mathrm{A})$ the sulphuric acid concentration in $\mathrm{M}$, (B) the sulphuric acid concentration in $\mathrm{M},(\mathrm{C})$ the pulp density in $\%(\mathrm{w} / \mathrm{v})$, and (D) the contact time in hours. Within the range of low and high values of the parameters studied, a non-linear optimization protocol was followed per the Monte-Carlo optimization procedure. Equation (2) was solved using the Monte-Carlo optimization technique and the results gave the optimum values for $\mathrm{Cu}$ leaching as: $3.92 \mathrm{M}$ Sulphuric acid, 3.93 M sulphuric acid, 6.98\% pulp density (w/v) and $3.7 \mathrm{~h}$ contact time.

Similarly, the regression equation for Au leaching is shown below in Equation 3.

$\mathrm{Y}=-1.30+155.1 \mathrm{~A}+10.16 \mathrm{~B}-12.57 \mathrm{C}-0.304 \mathrm{D}$

$+0.464 \mathrm{E}-1844 \mathrm{~A}_{2}-9.16 \mathrm{~B}_{2}+6.75 \mathrm{C}_{2}-0.0928 \mathrm{D}_{2}-0.0364 \mathrm{E}_{2}-58.3 \mathrm{AB}-25.0 \mathrm{AC}-2$ $.55 \mathrm{AD}+3.93 \mathrm{AE}+0.4 \mathrm{BC}+1.703 \mathrm{BD}-1.078 \mathrm{BE}+1.402 \mathrm{CD}+0.714 \mathrm{CE}$

$+0.0455 \mathrm{DE}$

Where $\mathrm{Y}$ represents Au yield in (mg/100 mg PCB), (A) CuSO4 concentration in $\mathrm{M}$, (B) $\left(\mathrm{S}_{2} \mathrm{O}_{3}^{2-}\right)$ concentration in $\mathrm{M}$, (C) Ammonium hydroxide concentration in $\mathrm{M}$, (D) contact time (E) pulp density. Equation (2) was solved using the Monte-Carlo optimization technique and the results gave the optimum values for $\mathrm{Au}$ leaching as: $0.038 \mathrm{M}$ Copper sulphate, $0.3 \mathrm{M}\left(\mathrm{S}_{2} \mathrm{O}_{3}^{2-}\right), 0.38 \mathrm{M}$ Ammonium hydroxide, $10.76 \%(\mathrm{w} / \mathrm{v})$ pulp density and 6.73 hours contact time.

\section{Interaction plots and surface plots}

The interactions between the different process parameters (fitted means and data means) and their influence on the responses for final $\mathrm{Cu}$ and $\mathrm{Au}$ yields are given in Figure 2. The interaction plots showed the reciprocal effect of each process parameter. Arguably, the interaction effect between the Hydrogen sulphate concentration and sulphuric acid was very significant for $\mathrm{Cu}$ leaching. These two parameters are the two most significant in $\mathrm{Cu}$ leaching, thus their interactions with the other parameters, e.g., with pulp density, and contact time are significant as well. The interaction between pulp density and time, on the other hand, has a little effect on $\mathrm{Cu}$ leaching. An increase of pulp density from 2.0 to $6.0 \%(\mathrm{w} / \mathrm{v})$ had an insignificant effect on the final $\mathrm{Cu}$ yield. Similarly, the increase of contact time from 1.0 to 6.0 hours did not have a significant effect on the final yield. The variation of those two parameters had a relative low influence on the final $\mathrm{Cu}$ yield (Figure 2a).

The interaction between the leachant, the oxidant and the catalyzer concentrations had a direct effect on the final Au yield. However, the effect of contact time and pulp density was not very significant (Figure $2 \mathrm{~b}$ ). These results showed similarity with $\mathrm{Cu}$ leaching, where physical parameters, e.g., pulp density and time, played a less significant role than the concentrations of the reagents. $\left(\mathrm{S}_{2} \mathrm{O}_{3}^{2-}\right)$ was arguably the most significant parameter for the yield. Therefore, its interaction with the other parameters significantly affected the final leaching efficiency. The interaction of $\left(\mathrm{S}_{2} \mathrm{O}_{3}^{2-}\right)$ and Ammonium hydroxide concentrations had a very significant effect on Au leaching (Figure 2b).

When the concentrations of sulphuric acids were increased, from $-a$ value to $+\alpha$, the $\mathrm{Cu}$ yield increased to higher values and eventually 
Citation: Isildar A, Rene ER, Hullebusch EDV, Lens PNL (2017) Two-Step Leaching of Valuable Metals from Discarded Printed Circuit Boards, and Process Optimization Using Response Surface Methodology. Adv Recycling Waste Manag 2: 132. doi:10.4172/2475-7675.1000132

Page 5 of 9

reached maximum extraction yield of $262 \mathrm{mg} \mathrm{Cu} / \mathrm{g} \mathrm{PCB}$ at $3.92 \mathrm{M}$ sulphuric acid and $3.93 \mathrm{M}$ sulphuric acid concentration at constant optimal values of pulp density and contact time. Similarly, a statistically significant interaction between sulphuric acid and PD was observed when sulphuric acid was kept constant at the optimal value $(3.93 \mathrm{M})$. The effect of these parameters on the $\mathrm{Cu}$ yield significant, up to the optimal concentrations of these reagents. The effect, however, was found to be insignificant or negative, exceeding the optimal concentrations, as the increase of the concentration above the optimal value affected the yield negatively. Furthermore, sulphuric acid had a positive effect on the yield when the concentration of $\mathrm{H}_{2} \mathrm{SO}_{4}$ was also increased and the contact time was kept constant (Figure 3).

Concerning the final Au yield, an increase in the concentrations $\left(\mathrm{S}_{2} \mathrm{O}_{3}^{2-}\right)$ and Copper sulphate, from $-\alpha$ value toward $+\alpha$ (Table 1), resulted in a higher final Au yield. Maximum Au yield of $320 \mathrm{mg}$ $\mathrm{Au} / 100 \mathrm{~g}$ PCB was achieved at the optimal values of $0.038 \mathrm{M} \mathrm{CuSO} 4$, $0.3 \mathrm{M}\left(\mathrm{S}_{2} \mathrm{O}_{3}^{2-}\right), 0.38 \mathrm{M}$ Ammonium hydroxide, at constant optimal pulp density and contact time values. $\mathrm{NH}_{4}^{+}$concentration has a less prevalent effect than the other two chemical, and its interaction with $\left(\mathrm{S}_{2} \mathrm{O}_{3}^{2-}\right)$ had a small effect on Au yield (Figure 4).

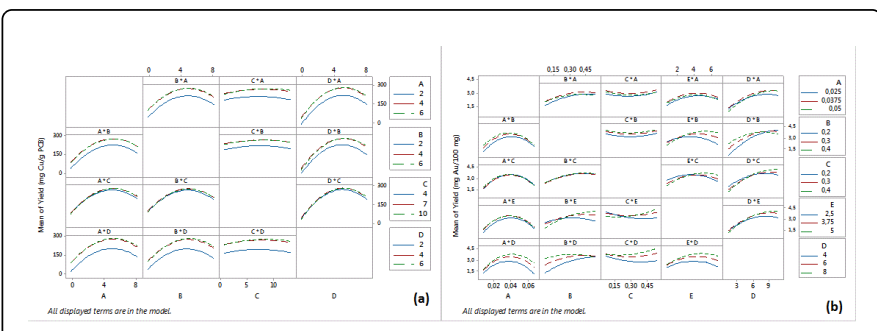

Figure 2: Interaction plot for the variable process parameters for (a) $\mathrm{Cu}$ leaching process (A) $\mathrm{H}_{2} \mathrm{SO}_{4}(\mathrm{M})$, (B) sulphuric acid (M), (C) pulp density (\%), w/v, and (D) contact time (h), and (b) Au leaching process (A) $\mathrm{CuSO}_{4}(\mathrm{M}),(\mathrm{B}) \mathrm{NH}_{4} \mathrm{OH}(\mathrm{M})$, (C) pulp density (\%, $\mathrm{w} / \mathrm{v})$, and (D) contact time.

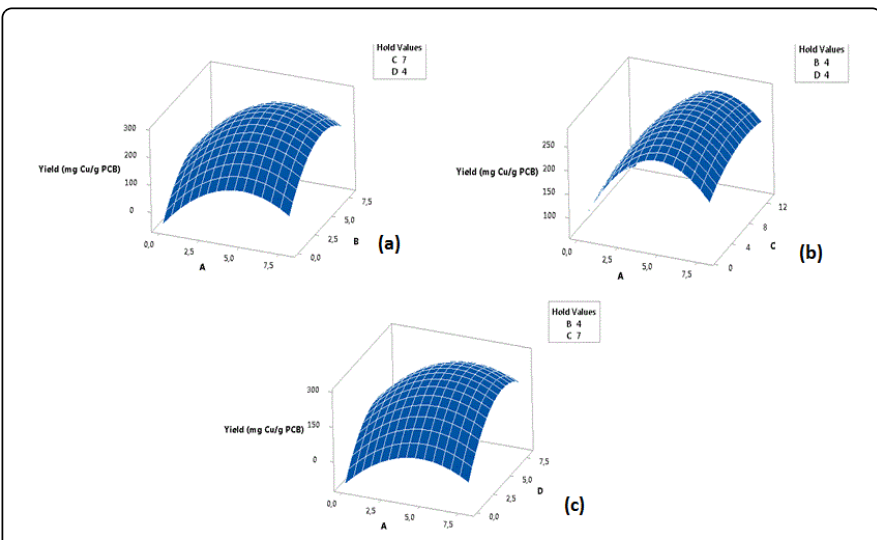

Figure 3: Surface plots of $\mathrm{Cu}$ extraction yield versus for $\mathrm{H}_{2} \mathrm{SO}_{4}(\mathrm{M})$, $\mathrm{H}_{2} \mathrm{SO}_{4}(\mathrm{M})$, (PD) $(\%, w / v)$, and contact time thiosulfate and (a) pulp density (PD) (\%, w/v) (b) time and (c) ammonium thiosulfate $\left(\mathrm{NH}_{4} \mathrm{OH}\right)$.

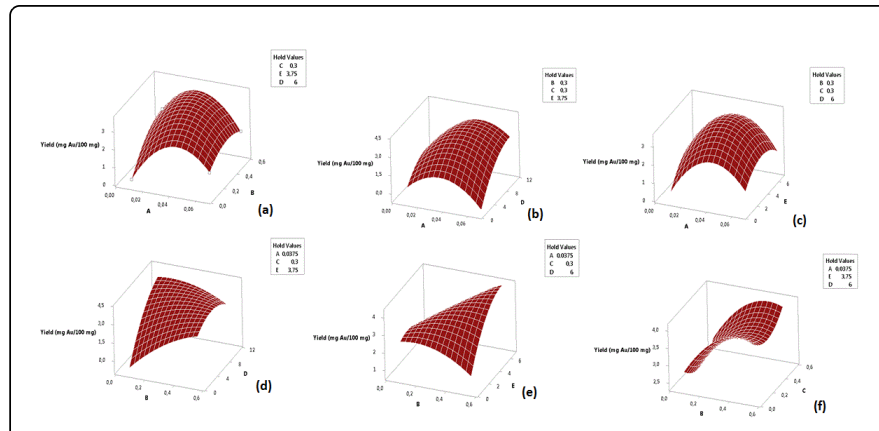

Figure 4: Surface plots of gold extraction yield versus for (A) thiosulfate and (a) pulp density (PD) (\%, w/v) (b) time and (c) ammonium thiosulfate $\left(\mathrm{NH}_{4} \mathrm{OH}\right)$.

\section{Leaching of copper in oxidative medium}

Confirmatory leaching tests were carried out to compare the validity and the reliability of the model predictions with the experimental data. The reciprocal interaction of the process parameters and the yield at optimal process parameters were investigated. The dissolution of $\mathrm{Cu}$ from discarded PCB at various process parameters as a function of time is demonstrated in Figure 5. The increase of the leachant and the oxidant concentrations resulted in a significant increase of $\mathrm{Cu}$ dissolution from the waste material. At optimal parameters of $3.93 \mathrm{M}$ sulphuric acid, $6.98 \%(\mathrm{w} / \mathrm{v})$ pulp density and $4 \mathrm{~h}$ contact time, $99.2 \%$ of $\mathrm{Cu}$ was dissolved.

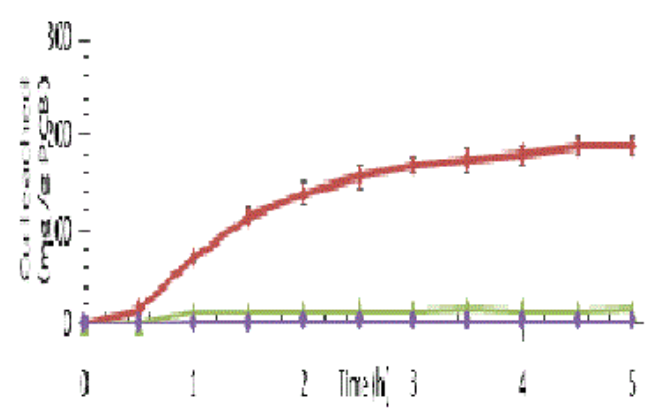

Figure 5: Leaching of copper $(\mathrm{Cu})$ as a function of time with $3.92 \mathrm{M}$ $\mathrm{H}_{2} \mathrm{SO}_{4}+3.93 \mathrm{M}$ sulphuric acid, $2.0 \mathrm{M} \mathrm{H}_{2} \mathrm{SO}_{4}+2.0 \mathrm{M}$ sulphuric acid, $3.92 \mathrm{M} \mathrm{H}_{2} \mathrm{SO}_{4}+0.0 \mathrm{M}$ sulphuric acid, $0.0 \mathrm{M} \mathrm{H}_{2} \mathrm{SO}_{4}+3.93 \mathrm{M}$ sulphuric acid at $6.98 \%(\mathrm{v} / \mathrm{w})$ pulp density.

During the confirmatory tests, an increase in temperature was observed, as the surface of the Erlenmeyer flasks became considerably warm. However, the temperature increase was not measured. This increase was due to the exothermic reaction between the leachantoxidant mixture and the metallic particles. Without the addition of oxidizing agents or heating of the solution, the leaching efficiency of $\mathrm{Cu}$ was observed to be very low and virtually insignificant. Without the addition of the oxidant sulphuric acid, $6.52 \%$ of $\mathrm{Cu}$ was leached form the waste material. Furthermore, without the addition of sulphuric acid was not able to leach $\mathrm{Cu}$ from the waste material. Without the addition of the oxidant sulphuric acid, the oxidative potential of the leachant solution was not high enough to oxidize elemental copper found in the 
Page 6 of 9

discarded PCB to cupric cations. Similarly, without the addition of the leachant, $\mathrm{Cu}$ dissolution into the leachate solution was insignificant. In negative control tests without addition of the neither the leachant nor the oxidant, $\mathrm{Cu}$ leaching was not observed (results not shown). Leaching of gold in ammoniacal thiosulfate medium.

Similar to the $\mathrm{Cu}$ leaching, confirmatory leaching tests were also carried out to validate the RSM model predictions for the Au leaching. Under optimal operational conditions of $0.3 \mathrm{M}\left(\mathrm{S}_{2} \mathrm{O}_{3}^{2-}\right), 0.38 \mathrm{M}$ Ammonium hydroxide and $10.76 \%(\mathrm{w} / \mathrm{v})$ pulp density, $58.2 \%$ and $71.4 \%$ of the $\mathrm{Au}$ was leached at the end of the 2 nd and the 4 th hour. Eventually $92.2 \%$ of the $\mathrm{Au}$ was dissolved in 7 hours under optimal conditions. The kinetic characteristics of the leaching process showed a typical concave curve (Figure 6).The varying $\left(\mathrm{S}_{2} \mathrm{O}_{3}^{2-}\right)$ concentration had a significant impact on $\mathrm{Au}$ leaching yield. In the confirmatory tests, the concentration of $\left(\mathrm{S}_{2} \mathrm{O}_{3}^{2-}\right)$ was varied in the range 0.1 to 0.3 $\mathrm{M}$, while the ions concentrations were kept constant at their optimal values. Lower $\left(\mathrm{S}_{2} \mathrm{O}_{3}^{2-}\right)$ concentrations than the optimal value resulted in a lower $\mathrm{Au}$ yield. $51.8 \%$ and $77.0 \%$, of the total $\mathrm{Au}$ was leached respectively at 0.1 and $0.2 \mathrm{M}$ of $\left(\mathrm{S}_{2} \mathrm{O}_{3}^{2-}\right)$. In control tests without $\left(\mathrm{S}_{2} \mathrm{O}_{3}^{2-}\right)$ addition, no Au leaching was detected (results not shown), which indicated that the $\left(\mathrm{S}_{2} \mathrm{O}_{3}^{2-}\right)$ concentration was the main factor in Au leaching.

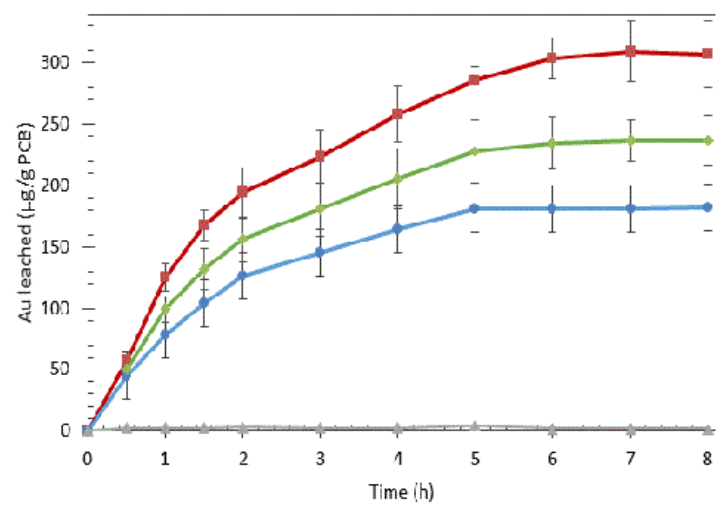

Figure 6: Leaching of gold $(\mathrm{Au})$ with $0.038 \mathrm{M} \mathrm{CuSO}_{4}+0.3 \mathrm{M}$ thiosulphate $+0.38 \mathrm{M} \mathrm{NH}_{4} \mathrm{OH}, 0.038 \mathrm{M} \mathrm{CuSO}_{4}+0.2 \mathrm{M} \mathrm{S}_{2} \mathrm{O}_{3}+0.38 \mathrm{M}$ $\mathrm{NH}_{4} \mathrm{OH}, 0.025 \mathrm{M} \mathrm{CuSO}_{4}+0.3 \mathrm{M}$ thiosulphate+0.38 $\mathrm{M} \mathrm{NH}_{4} \mathrm{OH}$, $0.025 \mathrm{M} \mathrm{CuSO}_{4}+0.0 \mathrm{M}$ thiosulphate $+0.38 \mathrm{M} \mathrm{NH}_{4} \mathrm{OH}$ as a function of time, and at $10.76 \%(\mathrm{v} / \mathrm{w})$ pulp density.

Varying the copper concentration, influenced the final yield but not on the kinetics of the leaching reaction. Lower copper concertation $(0.025 \mathrm{M})$ resulted in lower $\mathrm{Au}(59.4 \%)$ extraction yield compared to optimal values, when the other operational parameters are kept constant (Figure 7). Without copper addition, dissolution took place but only $21.4 \%$ of Au was dissolved (results not shown). The rate was found to decrease with time as the $\mathrm{Cu}$ concentration decreased.

The relative error between the measured data of the confirmation experiments and the calculated results of the models was $97.2 \%$ for $\mathrm{Cu}$ and $97.3 \%$ for $\mathrm{Au}$, respectively. The regression of the model predictions and the experimental data is given in Figure 7. Since the value predicted by the model was within the $95 \%$ confidence interval, this can be taken as confirmation of the suitability of the regression model for predictive purposes. Therefore, the RSM approach and CCD developed in this study provides reliable predictive data for the $\mathrm{Cu}$ and $\mathrm{Au}$ leaching. In a future scale-up procedure, a sensitivity analysis would be required.

\section{Discussion}

\section{Optimization of the process parameters for copper and gold leaching from discarded PCB}

Selective metal recovery from such a complex anthropogenic polymetallic secondary resource requires a novel approach for the development of an efficient metal recovery process. Diversity of metals and complexity of metal-metal and metal-non-metal associations inflict specific challenges. Hydrometallurgical processes enable relatively low capital costs, no hazardous gas emission, operational selectivity for small scale applications, and are propitious alternatives to conventional pyrometallurgical processes for metal recovery. In this work, a two-step approach to sequentially leach copper $(\mathrm{Cu})$ and gold $(\mathrm{Au})$ from a high-grade PCB is proposed.

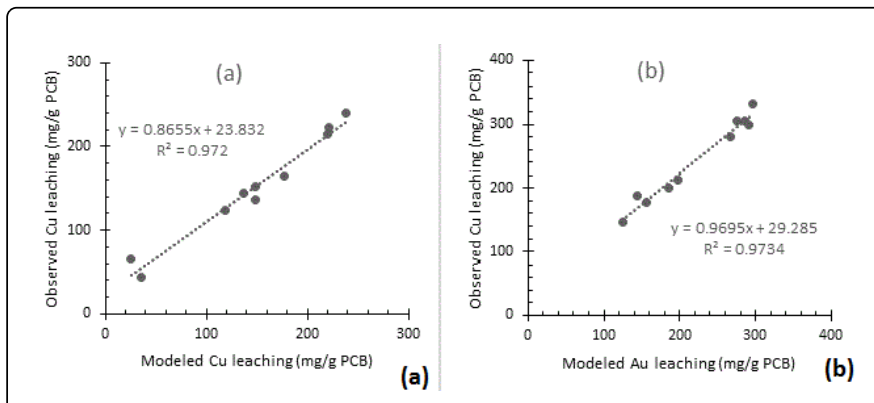

Figure 7: Regression analysis of the model prediction with the measured data for (a) $\mathrm{Cu}$ leaching and (b) Au leaching.

Response surface methods (RSM) is a collection of mathematical and statistical techniques used for developing, improving and optimizing the processes (DoE) particularly in complex hydrometallurgical metal extraction process where multiple independent variables are involved. At the initial stage of the process development, RSM revealed the optimal conditions and interaction of the process variables where maximal yield of desired products can be achieved. It produces statistically-validated predictive models, interaction plots of the independent variables and, response surface maps that point the way to pinnacles of the process performance.

The reagent concentrations are more significant factors than the other process variables in hydrometallurgical extraction of valuable metals from discarded PCB at high pulp densities (5-10\%, w/v). This applied to both to the leaching of $\mathrm{Cu}$ and $\mathrm{Au}$. The optimum concentrations of the leachant and the oxidant, e.g., sulphuric acid for $\mathrm{Cu}$ leaching and the leachant, e.g., $\left(\mathrm{S}_{2} \mathrm{O}_{3}^{2-}\right)$ for Au, played a dominant role during the leaching of these valuable metals. In addition, there were significant interaction between sulphuric acid for $\mathrm{Cu}$ and between $\left(\mathrm{S}_{2} \mathrm{O}_{3}^{2-}\right)$ and $\mathrm{Cu}$ for $\mathrm{Au}$. The effect of PD and time were rather less prominent for both $\mathrm{Cu}$ and $\mathrm{Au}$ extraction yield. Furthermore, the 
results indicated that the interaction between leachants and the other independent variables was statistically insignificant. Thus, the maximal metal yield from discarded PCB did not depend on the level of PD and the contact time. This does, however, not translate into the insignificance of these parameters, but in a much smaller influence of them on the final yield.

The analysis of variance (ANOVA) showed that the response surface quadratic model was significant at $F$ value of 5.04 and a $P$ values of $<0.0001$. The statistical significance of the model was also confirmed by the determination of coefficient $(\mathrm{R} 2=0.911)$ which indicated that only $8.1 \%$ of the variations were not explained by the model and this also means that $91 \%$ of the variations were explained by the independent variables. The model prediction and the optimized values were in good agreement. One exception was the effect of ammonium hydroxide concentration on Au yield, the model predicted a positive correlation between the Au extraction yield concentration above the optimal value (Figure 2). However, in the confirmatory tests it had insignificant effect (Figure 6).

\section{Characterization of discarded PCB}

Telecom devices PCB showed differences from consumer electronics PCB such as regular personal computers in terms of metals concentrations (Table 2). Typically, they have higher concentrations of $\mathrm{Cu}$ and $\mathrm{Au}$, along with other valuable metals. The economic value of $\mathrm{Cu}$ and $\mathrm{Au}$ constituted the most of the total value (98.1\%) of the discarded telecom PCB. Thus, the main economic motivation for PCB recycling is the selective and efficient recovery of $\mathrm{Cu}$ and $\mathrm{Au}$. These two metals react similarly in hydrometallurgical reaction and a prevalent competition is usually observed. Thus, an innovative strategy is required for the processing of polymetallic high grade secondary source for metal recovery.

The $\mathrm{Cu}$ fraction is overlaid by laminate layers in multilayer PCB, the most widely used type of boards, which inhibit the contact between the leaching medium and $\mathrm{Cu}$. Thus, liberation of the components and the $\mathrm{Cu}$ layer is required to the largest extent possible, which is typically carried out by mechanical crushing of the discarded boards in specialized comminution equipment. Au is found predominantly on the central processing unit (CPU), up to $96 \%$ of this element is found on these central units. Therefore, comminution and pre-treatment will result in loss of precious metals. In metal assay studies, the relatively low Au content of the CPU-removed desktop PCB (Table 1) confirmed these findings. The rest of the Au is found in the contact layers of these boards, typically built intact with the board matrix and is most efficiently separated by a selective leaching process. Telecom PCB contain $\mathrm{Au}$ as a contact material at the backside of their top layer and do not contain visible conventional CPU.

The metal concentrations varied largely per particle sizes (Table 1), which is of practical significance for the selection and design of a pretreatment step. argues that the conventional crushers are not wellsuited to cut and crush such a friable and brittle material. Also, sieving to smaller than $0.5 \mathrm{~mm}$ leads to the loss of the material, presumably on the sieve and thus accumulation of certain metals can occur on certain mesh sizes. Physical pre-treatment of discarded PCB leads to significant material losses. Physical separation processes can be used ahead of hydrometallurgical processes at the expense of metal losses. In addition to the optimization of the leaching and purification steps, it is recommended to also optimize the physical pre-treatment, perhaps with more advanced equipment designed to process such material and particle size distributions.

\section{Leaching of $\mathrm{Cu}$ from the discarded PCB}

Most metals in WEEE are found in their elemental form, or as alloys, distinctive to primary ores. This is of practical significance for the development of a metal recovery process. An oxidative leaching process is essential for the extraction of valuable metals from their primary ores and also secondary raw materials. Concentrations of sulphuric acid were the main process variables that control the extraction of $\mathrm{Cu}$ from the waste material, as was predicted by the optimization model and confirmed in the confirmatory experiments. The higher dosage of sulphuric acid can release more $\mathrm{Cu}$ through proton attack (4) and sulphuric acid provides an oxidative medium (5) to facilitate the leaching of $\mathrm{Cu}$ into the solution. The overall reaction is given in Equation (6).

$$
\begin{aligned}
& \mathrm{Cu}^{0}+2 \mathrm{H}^{+} \rightarrow \mathrm{Cu}^{2+}+\mathrm{H}_{2} \Delta \mathrm{G}^{0}=65.5 \mathrm{~kJ} / \mathrm{mol}(4) \\
& \mathrm{Cu}^{0}+1 / 2 \mathrm{O}_{2}+2 \mathrm{H}^{+} \rightarrow \mathrm{Cu}^{2+}+\mathrm{H}_{2} \mathrm{O} \Delta \mathrm{G}^{0}=-171.63 \mathrm{~kJ} / \mathrm{mol}(5) \\
& \mathrm{Cu}+\text { sulphuric acid+Sulphuric acid } \rightarrow \mathrm{Cu}+\mathrm{SO}_{4}^{2-}+\mathrm{H} 2 \mathrm{O} \Delta \mathrm{GO}=-329.7 \\
& \mathrm{~kJ} / \mathrm{mol}
\end{aligned}
$$

Leaching of $\mathrm{Cu}$ from PCB in the absence and the presence of the oxidant in acidic sulfate media showed a difference in metal mobilization. In the $\mathrm{H}_{2} \mathrm{SO}_{4}$ leaching system, addition of sulphuric acid significantly increased the $\mathrm{Cu}$ dissolution rate. In fact, without the addition of the oxidant, $\mathrm{Cu}$ cannot be effectively leached into solution. A very limited $\mathrm{Cu}$ extraction (2\%) in the absence of the oxidant (Figure 5 ) is consistent with the thermodynamic information, as in Equations (4), (5), and (6). Leaching of elemental $\mathrm{Cu}$ with sulfuric acid is not thermodynamically favorable (4) and an addition of an oxidant is required. Moreover, the presence of sulphuric acid as a strong oxidant is likely to prevent the reduction or precipitation of the oxidized metal species in the solution

\section{Leaching of Au from the discarded telecom PCB}

The dissolution of Au from discarded PCB in $\mathrm{NH}_{4}^{+}$medium is a process mediated by the concentration of $\left(\mathrm{S}_{2} \mathrm{O}_{3}^{2-}\right)$ in the presence of $\mathrm{Cu}$ ions as the oxidant. $\mathrm{Cu}$ ions create the thermodynamically possible conditions for the leaching of gold into the solution. The major role of $\mathrm{NH}_{4}^{+}$in the thiosulfate system is to stabilize $\mathrm{Cu}$ ions. The Au leaching solution includes the thermodynamically stable cupric-tetraamine complex because of the mixture of the Copper sulphate and Ammonia in aqueous medium as shown below:

$$
\begin{aligned}
& \mathrm{Cu}^{2+}+4 \mathrm{NH}_{3} \leftrightarrow \mathrm{Cu}\left(\mathrm{NH}_{3}\right)_{4}^{2+} \mathrm{Kf}: 2.1 \times 1013(7) \\
& \text { The cupric-tetraamine }\left(\mathrm{Cu}\left(\mathrm{NH}_{3}\right)_{4}^{2+}\right) \text { complex is a }
\end{aligned}
$$

thermodynamically stable species which enhances the stability region of $\mathrm{Cu}(\mathrm{II})-\mathrm{Cu}(\mathrm{I})$, preventing the reduction of $\mathrm{Cu}$ into solid compounds. Thus, the $\mathrm{Cu}$ concentration of the Au leaching solution is an important factor for the thermodynamical stability of the solution. The CCD model corroborated a high correlation of $\mathrm{Cu}$ concentration and $\mathrm{Au}$ yield (Figures $2 \mathrm{~b}$ and 6 ). In our confirmatory tests, the initial rate of gold extraction-within the first two hours-is enhanced with increasing $\mathrm{Cu}$ concentration, however, not significant above a certain concertation. Varying the $\mathrm{Cu}$ concentration, from 0.01 to $0.03 \mathrm{M} \mathrm{Cu}$, did not influence the predominant $\mathrm{Cu}$ species in the reaction system at 
Page 8 of 9

the same $\mathrm{Eh} / \mathrm{pH}$ conditions. Moreover, a very low $\mathrm{Au}$ dissolution efficiency was observed in the tests in the absence of $\mathrm{Cu}$ (Figure 6).

$\mathrm{Au}$ dissolution with $\left(\mathrm{S}_{2} \mathrm{O}_{3}^{2-}\right)$ occurs in presence of cuprictetraamine as the oxidant which forms stable $\mathrm{Au}\left(\mathrm{S}_{2} \mathrm{O}_{3}\right)_{2}^{3-}$ and

$$
\begin{aligned}
& \text { complexes, as shown below in Equation } \\
& \mathrm{Au}+5 \mathrm{~S}_{2} \mathrm{O}_{3}^{2-}+\mathrm{Cu}\left(\mathrm{NH}_{3}\right)_{4}^{2+} \rightarrow \mathrm{Au}\left(\mathrm{S}_{2} \mathrm{O}_{3}^{2-}\right)_{2}^{3-}+4 \mathrm{NH}_{3} \\
& +\mathrm{Cu}\left(\mathrm{S}_{2} \mathrm{O}_{3}^{2-}\right)_{3}^{5-}
\end{aligned}
$$

At the optimal conditions, the rate of Au dissolution was rapid during the first two hours of the reaction, then the extraction reached the steady state (Figure 6). The maximum gold recovery obtained was $96.22 \%$ after 7 hours of leaching. $\left(\mathrm{S}_{2} \mathrm{O}_{3}^{2-}\right)$ had a direct influence on gold leaching, as predicted by CCD model and verified in the confirmatory tests. Such a result is not surprising since the dissolution reaction Equation (8) is likely to be enhanced at increased thiosulfate concentrations. In terms of process development, a balance between leach kinetics and high thiosulfate consumption is required; an optimum value appears to be $0.38 \mathrm{M}$ from a high-grade $\mathrm{Cu}$ removed PCB. Varying the $\mathrm{NH}_{4}^{+}$content had an insignificant effect in our experimental conditions, while the kinetic curve showed the same shape. Earlier studies reported decreasing gold recovery with increasing the $\mathrm{NH}_{4}^{+}$concentration due to disturbed thermodynamic stability of $\mathrm{Cu}\left(\mathrm{NH}_{3}\right)_{4}^{2+}$. However, these studies reported concentrations much higher than the process variables optimized in this work. Leaching of gold from PCB in this concentration range of target metal, leachant and oxidant is found to be feasible. Conclusively the two-step approach, in which a potential competition between metals is prevented can be regarded as an efficient strategy to leach valuable metals from the waste material. Moreover, a two-step step extraction approach leads to two separate leachate solutions in different media which might be of practical importance to achieve selective recovery of metals from discarded PCB material.

\section{Conclusion}

Secondary raw materials are very complex and require a novel metal recovery approach. In this study, a two-step hydrometallurgical route for the extraction of $\mathrm{Cu}$ and $\mathrm{Au}$ from a high-grade PCB was developed. The PCB material contained containing $260 \mathrm{mg} / \mathrm{g} \mathrm{Cu}$ and $0.320 \mathrm{mg} / \mathrm{g}$ $\mathrm{Au}$. A two-step $\mathrm{Cu}$ and $\mathrm{Au}$ extraction procedure was designed and optimized by RSM using the CCD technique. The model accurately predicted the yields under various operational conditions with high coefficients of determination between the response and the process variables. In confirmatory tests, $99.2 \%$ and $92.2 \%$ of $\mathrm{Cu}$ and $\mathrm{Au}$ was extracted, respectively, under the optimized conditions. Oxidative acid leaching for the extraction of $\mathrm{Cu}$ from discarded PCB is a kinetically fast and efficient technology. A mixture of an oxidant and a leachant is required for efficient $\mathrm{Cu}$ extraction from the waste material. The leaching of $\mathrm{Au}$ in ammoniacal thiosulfate solutions was chemically controlled.

\section{Acknowledgement}

The authors thank Dr. Chloé Foudrin for her kind contribution to the analytical work. This work was carried out with financial support through the Erasmus Mundus Joint Doctorate Programme ETeCoS3 (Environmental Technologies for Contaminated Solids, Soils and Sediments, grant agreement FPA no 2010-0009) supported by the European Commission (EC).

\section{References}

1. Marques AC (2013) Printed circuit boards: A review on the perspective of sustainability. J Environ Manage 131: 298-306.

2. Duan H, Hou K, Li J, Zhu X (2011) Examining the technology acceptance for dismantling of waste printed circuit boards in light of recycling and environmental concerns. J Environ Manage 92: 392-399.

3. Yamane LH, de Moraes VT, Espinosa DCR, Tenório JAS (2011) Recycling of WEEE: Characterization of spent printed circuit boards from mobile phones and computers. Waste Manag 31: 2553-2558.

4. Zhang K, Schnoor JL, Zeng EY (2012) E-Waste recycling: Where does it go from here. Environ Sci Technol 46: 10861-10867.

5. Ongondo FO, Williams ID, Whitlock G (2015) Distinct Urban Mines: Exploiting secondary resources in unique anthropogenic spaces. Waste Manag 45: 4-9.

6. StEP (2015) StEP E-waste World Map-European Union-STEP, StEP Ewaste World Map.

7. Baldé CP, Wang F, Kuehr R, Huisman J (2015) The Global E-Waste Monitor 2014. United Nations University, IAS-SCYCLE, Bonn, Germany.

8. Song Q, Li J (2014) Environmental effects of heavy metals derived from the e-waste recycling activities in China: A systematic review. Waste Manag 34: 2587-2594.

9. Oguchi M, Sakanakura H, Terazono A (2013) Toxic metals in WEEE: Characterization and substance flow analysis in waste treatment processes. Sci Total Environ 463: 1124-1132.

10. Van Eygen E, De Meester S, Tran HP, Dewulf J (2016) Resource savings by urban mining: The case of desktop and laptop computers in Belgium. Resour Conserv Recycl 107: 53-64.

11. Bloodworth A (2014) Track flows to manage technology-metal supply. Nature 505: 9-10.

12. Reck BK, Graedel TE (2012) Challenges in Metal Recycling. Science 337: 690-695.

13. Bigum M, Brogaard L, Christensen TH (2012) Metal recovery from highgrade WEEE: A life cycle assessment. J Hazard Mater 207: 8-14.

14. Hagelüken C (2006) Improving metal returns and eco-efficiency in electronics recycling. Proc IEEE Int Symp Electron Environ pp: 218-223.

15. Wang X, Gaustad G (2012) Prioritizing material recovery for end-of-life printed circuit boards. Waste Manag 32: 1903-1913.

16. Tanskanen P (2013) Management and recycling of electronic waste. Acta Mater 61: 1001-1011.

17. Luda MP (2011) Recycling of Printed Circuit Boards. Integr Waste Manag 2: 285-298.

18. Schlesinger ME, King MJ, Sole KC, Davenport WG (2011) Extractive Metallurgy of Copper. (5th edn), Elsevier.

19. Havlik T, Orac D, Petranikova M, Miskufova A, Kukurugya F, et al (2010) Leaching of copper and tin from used printed circuit boards after thermal treatment. J Hazard Mater 183: 866-873.

20. Lee S, Yoo K, Jha MK, Lee J (2015) Separation of Sn from waste Pb-free $\mathrm{Sn}-\mathrm{Ag}-\mathrm{Cu}$ solder in hydrochloric acid solution with ferric chloride. Hydrometall 157: 184-187.

21. Rocchetti L, Vegliò F, Kopacek B, Beolchini F (2013) Environmental impact assessment of hydrometallurgical processes for metal recovery from WEEE residues using a portable prototype plant. Environ Sci Technol 47: 1581-1588. 
Citation: Isildar A, Rene ER, Hullebusch EDV, Lens PNL (2017) Two-Step Leaching of Valuable Metals from Discarded Printed Circuit Boards, and Process Optimization Using Response Surface Methodology. Adv Recycling Waste Manag 2: 132. doi:10.4172/2475-7675.1000132

Page 9 of 9

22. Yang H, Liu J, Yang J (2011) Leaching copper from shredded particles of waste printed circuit boards. J Hazard Mater 187: 393-400.

23. Janyasuthiwong S, Ugas R, Rene ER, Alessandra C, Esposito G (2016) Effect of operational parameters on the leaching efficiency and recovery of heavy metals from computer printed circuit boards. J Chem Technol Biotechnol 91: 2038-2046.

24. Joda N, Rashchi F (2012) Recovery of ultra fine grained silver and copper from PC board scraps. Sep Purif Technol 92: 36-42.

25. Xiao Y, Yang Y, Van Den Berg J, Sietsma J, Agterhuis H, et al. (2013) Hydrometallurgical recovery of copper from complex mixtures of end-oflife shredded ICT products. Hydrometall 140: 128-134.

26. Li J, Miller JD (2007) Reaction kinetics of gold dissolution in acid thiourea solution using ferric sulfate as oxidant. Hydrometall 89: 279-288.

27. Kim E, Kim M, Lee J, Jeong J, Pandey BD (2011) Leaching kinetics of copper from waste printed circuit boards by electro-generated chlorine in $\mathrm{HCl}$ solution. Hydrometall 107: 124-132.

28. Dai X, Breuer PL (2013) Leaching and electrochemistry of gold, silver and gold-silver alloys in cyanide solutions: Effect of oxidant and lead (II) ions. Hydrometall 133: 139-148.

29. Ha VH, Lee J, Jeong JC, Hai HT, Jha MK (2010) Thiosulfate leaching of gold from waste mobile phones. J Hazard Mater 178: 1115-1119.

30. Petter PMH, Veit HM, Bernardes AM (2014) Evaluation of gold and silver leaching from printed circuit board of cellphones. Waste Manag 34: 475-482.

31. Birloaga I, De Michelis I, Ferella F, Buzatu M, Vegliò F (2013) Study on the influence of various factors in the hydrometallurgical processing of waste printed circuit boards for copper and gold recovery. Waste Manag 33: 935-941.

32. Jing-ying L, Xiu-li X, Wen-quan L (2012) Thiourea leaching gold and silver from the printed circuit boards of waste mobile phones. Waste Manag 32: 1209-1212.
33. Sahin M, Akcil A, Erust C, Altynbek S, Gahan CS (2015) A potential alternative for precious metal recovery from E-waste: Iodine leaching. Sep Sci Technol 50: 2587-2595.

34. Serpe A, Rigoldi A, Marras C, Artizzu F, Mercuri L (2015) Chameleon behaviour of Iodine in recovering noble-metals from WEEE: towards sustainability and "zero" waste. Green Chem 17: 2208-2216.

35. Cui J, Zhang L (2008) Metallurgical recovery of metals from electronic waste: A review. J Hazard Mater 158: 228-256.

36. Wang Z, Guo S, Ye C (2016) Leaching of copper from metal powders mechanically separated from waste printed circuit boards in chloride media using hydrogen peroxide as oxidant. Procedia Environ Sci 31: 917-924.

37. Abbruzzese C, Fornari P, Massidda R, Vegliò F, Ubaldini S (1995) Thiosulphate leaching for gold hydrometallurgy. Hydrometall 39: 265-276.

38. Niu Z, Huang Q, Xin B, Qi C, Hu J, et al. (2016) Optimization of bioleaching conditions for metal removal from spent zinc-manganese batteries using response surface methodology. J Chem Technol Biotechnol 91: 608-617.

39. Liang G, Tang J, Liu W, Zhou Q (2013) Optimizing mixed culture of two acidophiles to improve copper recovery from printed circuit boards (PCBs). J Hazard Mater 250: 238-245.

40. Kolias K, Hahladakis JN, Gidarakos E (2014) Assessment of toxic metals in waste personal computers. Waste Manag 34: 1480-1487.

41. Tuncuk A, Stazi V, Akcil A, Yazici EY, Deveci H (2012) Aqueous metal recovery techniques from e-scrap. Hydrometall in Recycling Miner Eng 25: 28-37. 